See Article page 333.

\section{Commentary: Teamwork is needed to prevent aorto-conduit fistulas from being fatal}

\author{
Camilo Velasquez, MD, and Ikenna Okereke, MD
}

Andrew Feczko and colleagues ${ }^{1}$ have presented an interesting but dreaded complication of massive hemorrhage from an aorto-conduit fistula after esophagectomy. They detail the roles of endoscopy to diagnose the complication, angiography to localize the fistula, and surgery for definitive repair. Their algorithm simplifies the required steps for anyone encountering an upper gastrointestinal bleed in a patient with a history of esophagectomy. This algorithm is valuable for a broad group of physicians, as these patients may initially present to emergency room physicians, gastroenterologists, general surgeons, or thoracic surgeons. The entity's rarity can lead to a delay in diagnosis, often with fatal consequences. As such, it is important to take a multidisciplinary approach for evaluation and management to prevent mortality.

Conservative management or watchful waiting of an aorto-conduit fistula is always lethal, and the average period between the initial bleed and death from exsanguination is merely hours. ${ }^{2}$ A herald bleed in a patient with a history of esophagectomy should not be overlooked, as a delay can lead to exsanguination if immediate action is not taken. The triad of chest pain, sentinel hemorrhage, and exsanguination first described by Chiari is associated with a high fatality rate., Given this high rate of death, an upper gastrointestinal bleed after esophagectomy should raise the suspicion of an aorto-conduit fistula.

From the Division of Cardiothoracic Surgery, University of Texas Medical Branch, Galveston, Tex.

Disclosures: The authors reported no conflicts of interest.

The Journal policy requires editors and reviewers to disclose conflicts of interest and to decline handling or reviewing manuscripts for which they may have a conflict of interest. The editors and reviewers of this article have no conflicts of interest.

Received for publication Feb 9, 2021; revisions received Feb 9, 2021; accepted for publication Feb 18, 2021; available ahead of print Feb 27, 2021.

Address for reprints: Ikenna Okereke, MD, Division of Cardiothoracic Surgery, University of Texas Medical Branch, 301 University Blvd, Galveston, TX 77555 (E-mail: ikokerek@utmb.edu).

JTCVS Techniques 2021;7:336-7

2666-2507

Copyright (c) 2021 The Authors. Published by Elsevier Inc. on behalf of The American Association for Thoracic Surgery. This is an open access article under the CC BY-NCND license (http://creativecommons.org/licenses/by-nc-nd/4.0/).

https://doi.org/10.1016/j.xjtc.2021.02.021

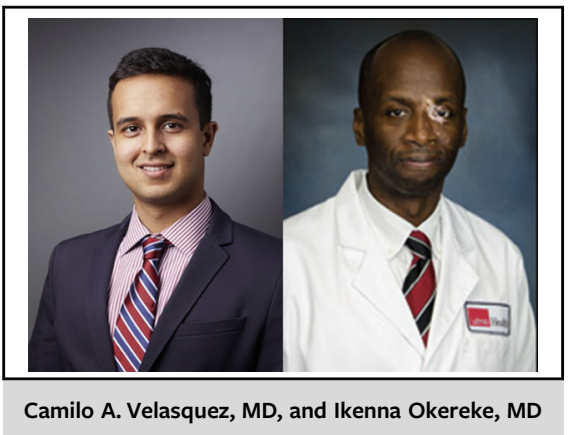

CENTRAL MESSAGE

Aorto-conduit fistula after

esophagectomy is a rare and

grave complication. Prompt

diagnosis and rapid fistula con-

trol is the necessary treatment. A

multidisciplinary approach will

improve survival.

Endovascular techniques can act as temporizing maneuvers to allow stabilization of the patient and definitive repair of the fistula. During surgery, the first goal should be to control the bleeding from the aorta. Thereafter, the gastric conduit can be repaired, and a buttressed flap can be placed between the conduit and the aorta. ${ }^{5}$ In their report, Feczko and colleagues describe using an endovascular balloon to occlude the aorta. This strategy controlled bleeding long enough to repair the aorta. Indeed, the use of an occlusive balloon within the aorta highlighted an efficient multidisciplinary approach and prevented mortality. This technique of intra-aortic balloon occlusion is extensively used by trauma teams ${ }^{6}$ and was nicely applied in this situation.

Another possible option for vascular control is thoracic endovascular aortic repair (TEVAR). TEVAR can quickly control hemorrhage and act as a bridge to surgery. ${ }^{7}$ In this case, TEVAR was not used because of the risk of occluding the celiac axis, given the unusually low position of the fistula. But for most aorto-conduit fistulas, TEVAR is an option to consider.

Although a multidisciplinary approach will temporize bleeding, operative intervention is the mainstay of treatment of an aorto-conduit fistula. Autologous tissue should be used whenever possible to separate the aorta from the conduit following repair. Repairing the fistula in one stage is ideal, but in an unstable patient, repairing the aorta initially is adequate. The surgical area can be drained, and 
the conduit can be repaired within days once the patient has become more stable.

Prompt recognition and a multidisciplinary approach to aorto-conduit fistulas are essential to prevent mortality. Although this complication is highly lethal, involving multiple service lines will improve the chances of survival.

\section{References}

1. Fezcko AF, Sudarshan M, Smolock CJ, Raja S. Successful management of aorto-conduit fistula after esophagectomy: Tips and tricks to avoid catastrophe. J Thorac Cardiovasc Surg Tech. 2021;7:333-5.

2. Strong S, Higgs S, Streets C, Titcomb D, Barham P, Blazeby J, et al. Aorto-conduit fistula developing four years after esophagectomy. J Surg Case Rep. 2012;2012:8.
3. Yamazato T, Nakamura T, Abe N, Yokawa K, Ikeno Y, Koda Y, et al. Surgical strategy for the treatment of aortoesophageal fistula. J Thorac Cardiovasc Surg. 2018; 155:32-40.

4. Chiari H. Ueber fremdkoreverletzung des oesophagus mit aortenperforation. Ber Klin Wochenschr. 1914;51:7-9 [in German].

5. Sugiyama K, Iwahashi T, Koizumi N, Nishibe T, Fujiyoshi T, Ogino H. Surgical treatment for secondary aortoesophageal fistula. J Cardiothorac Surg. 2020;15: 251

6. van der Burg BLS, van Dongen TTC, Morrison JJ, Hedeman Joosten PPA, DuBose JJ, Hörer TM, et al. A systematic review and meta-analysis of the use of resuscitative endovascular balloon occlusion of the aorta in the management of major exsanguination. Eur J Trauma Emerg Surg. 2018;44: $535-50$.

7. Kawamoto S, Sato M, Motoyoshi N, Kumagai K, Adachi O, Saito T, et al. Outcomes of a staged surgical treatment strategy for aortoesophageal fistula. Gen Thorac Cardiovasc Surg. 2015;63:147-52. 